\title{
A multi-objective fuzzy mathematical approach for sustainable reverse supply chain configuration
}

\begin{tabular}{|c|c|}
\hline $\begin{array}{l}\text { Authors: } \\
\text { Jyoti D. Darba } \\
\text { Vernika Agarw } \\
\text { Venkata S.S. Y } \\
\text { Diego Galar } \\
\text { Prakash C. Jha }\end{array}$ & $\mathrm{al}^{1}$ (1) \\
\hline $\begin{array}{l}\text { Affiliations: } \\
{ }^{1} \text { Department } \\
\text { Research, Uni } \\
\text { Delhi, India }\end{array}$ & $\begin{array}{l}\text { Operational } \\
\text { ersity of }\end{array}$ \\
\hline $\begin{array}{l}{ }^{2} \text { Department } \\
\text { and Systems } E \\
\text { University of } P \\
\text { South Africa }\end{array}$ & $\begin{array}{l}\text { f Industrial } \\
\text { ngineering, } \\
\text { retoria, }\end{array}$ \\
\hline $\begin{array}{l}{ }^{3} \text { Division of Or } \\
\text { Maintenance } \\
\text { Luleå Universi } \\
\text { Technology, Sv }\end{array}$ & $\begin{array}{l}\text { eration and } \\
\text { ngineering, } \\
y \text { of } \\
\text { veden }\end{array}$ \\
\hline $\begin{array}{l}\text { Correspondin } \\
\text { Jyoti Darbari, } \\
\text { jydbr@hotma }\end{array}$ & $\begin{array}{l}\text { author: } \\
\text { l.com }\end{array}$ \\
\hline $\begin{array}{l}\text { Dates: } \\
\text { Received: } 04 \text { S } \\
\text { Accepted: } 16 \\
\text { Published: } 27\end{array}$ & $\begin{array}{l}\text { ept. } 2016 \\
\text { eec. } 2016 \\
\text { Mar. } 2017\end{array}$ \\
\hline $\begin{array}{l}\text { How to cite th } \\
\text { Darbari, J.D., } \\
\text { Yadavalli, V.S.S } \\
\text { Jha, P.C., } 2017 \\
\text { objective fuzz } \\
\text { approach for s } \\
\text { reverse supply } \\
\text { configuration', } \\
\text { Transport and } \\
\text { Management } \\
\text { https://doi.org } \\
\text { jtscm.v11i0.26 }\end{array}$ & $\begin{array}{l}\text { is article: } \\
\text { garwal, V., } \\
\text {., Galar, D. \& } \\
\text { 'A multi- } \\
\text { mathematical } \\
\text { ustainable } \\
\text { chain } \\
\text { Journal of } \\
\text { Supply Chain } \\
11(0), \text { a267. } \\
710.4102 / \\
7\end{array}$ \\
\hline $\begin{array}{l}\text { Copyright: } \\
\text { (C) 2017. The A } \\
\text { Licensee: AOS } \\
\text { is licensed unc } \\
\text { Creative Comr } \\
\text { Attribution Lic }\end{array}$ & $\begin{array}{l}\text { uthors. } \\
\text { S. This work } \\
\text { ler the } \\
\text { lons } \\
\text { ense. }\end{array}$ \\
\hline Read online: & \\
\hline  & $\begin{array}{l}\text { Scan this QR } \\
\text { code with your } \\
\text { smart phone or } \\
\text { mobile device } \\
\text { to read online. }\end{array}$ \\
\hline
\end{tabular}

Background: Designing and implementation of reverse logistics (RL) network which meets the sustainability targets have been a matter of emerging concern for the electronics companies in India.

Objectives: The present study developed a two-phase model for configuration of sustainable RL network design for an Indian manufacturing company to manage its end-of-life and endof-use electronic products. The notable feature of the model was the evaluation of facilities under financial, environmental and social considerations and integration of the facility selection decisions with the network design.

Method: In the first phase, an integrated Analytical Hierarchical Process Complex Proportional Assessment methodology was used for the evaluation of the alternative locations in terms of their degree of utility, which in turn was based on the three dimensions of sustainability. In the second phase, the RL network was configured as a bi-objective programming problem, and fuzzy optimisation approach was utilised for obtaining a properly efficient solution to the problem.

Results: The compromised solution attained by the proposed fuzzy model demonstrated that the cost differential for choosing recovery facilities with better environmental and social performance was not significant; therefore, Indian manufacturers must not compromise on the sustainability aspects for facility location decisions.

Conclusion: The results reaffirmed that the bi-objective fuzzy decision-making model can serve as a decision tool for the Indian manufacturers in designing a sustainable RL network. The multi-objective optimisation model captured a reasonable trade-off between the fuzzy goals of minimising the cost of the RL network and maximising the sustainable performance of the facilities chosen.

\section{Introduction}

Resource depletion and e-waste generation through electronics use have reached an alarming stage in developing countries, posing a serious threat to the environment and human health (Wath, Dutt \& Chakrabarti 2011:260). During the last decade, there has been an exponential increase in the use of electronics in India, and most of these are discarded irresponsibly by consumers (Wath et al. 2011:252). In the framework of sustainable development, discarding the electronics products that are no longer in use by their original users is not a viable option (Achillas et al. 2010:870). Reverse logistics (RL) has gained immense relevance in this regard, as it plays a crucial role in utilising the residual value still existing in the discarded electronics. Disposing off the unwanted parts and materials responsibly is having a positive impact on the environment (Khor et al. 2016:97; Mutha \& Pokharel 2009:334). Though government regulations and policies in India require Original Electronics Manufacturers (OEMs) to incorporate sustainable recovery strategies for extending the entire life cycle of their products, consumer returns are still not managed by manufacturers but mostly by an informal sector involving 'kabadiwallahs', recyclers and dismantlers (Dwivedy \& Mittal 2012:230). Lack of government support and awareness among manufacturers, as well as consumers, are some of the major reasons for the disinterest of OEMs in India towards developing an efficient recovery system (Ravi \& Shankar 2015:887). The implementation of RL can be a costly endeavour as it involves the processes of collection, refurbishing, disassembly and reprocessing. Therefore, OEMs prefer outsourcing all the RL operations to specialised third-party reverse logistics providers (3PRLPs) (Subramoniam, Huisingh \& Chinnam 2010:1577). However, firms can seek to perform the RL operations independently or jointly with 3PRLs to gain maximum benefits from the returns (Agarwal et al. 2016:481). 
Recent years have witnessed the growing interest of OEMs in redesigning their logistics network for managing the RL activities sustainably. Although deriving maximum economic benefits from the returns is the primary objective of $\mathrm{RL}$, it inherently helps in creating a positive impact on the environment and society. Incorporating strategic recovery decisions within their logistics network can also help manufacturers enhance their bottom line. To begin with the process of implementation, it is fundamental for the OEM to focus on establishing new recovery facilities (RFs) and expanding existing facilities. The selection of location for setting up of facilities across the supply chain (SC) is an important decision, as it entails long-term cost obligations on the firms (Ertuğrul 2011:725). The right choice of location can assist the firm in gaining a competitive edge while simultaneously improving on the operational performance, not only in the short term but also in the long term. In this regard, the present article aims to contribute further to the area of RL network design problems, integrating optimal facility location decisions for creating a sustainable channel for consumer returns. Furthermore, in view of the growing concern for sustainable development, it has become increasingly important for the firms to incorporate all the sustainability factors in facility location decision making (Chen, Olhager \& Tang 2014:155). In this context, the main focus of the present work is to develop a mathematical model for designing a sustainable RL network from the OEM's perspective wherein the collection, inspection and repairing of returns is done by the OEM independently, and the other RL operations including disassembly, recycling and disposal are outsourced to 3PRLPs. For the purpose of establishing new centres for repair and refurbishing activities, few collection centres (CCs) are chosen for accommodating these activities. It would require appropriate expansion of the CCs depending on space availability, cost of expansion, available budget and the number of returns. The notable feature of the model is the evaluation of CCs under financial, environmental and social considerations and integration of the facility selection decisions within the network design. The CCs are evaluated taking into account qualitative and quantitative criteria based on the three dimensions of sustainability, using integrated multi-criteria decision making (MCDM), which combines the efficiencies of the Analytical Hierarchical Process (AHP) and the Complex Proportional Assessment (COPRAS) method. A fuzzy mixed integer linear programming model is proposed for determining the optimum number, locations and capacities of the RFs, penalty cost for underutilisation of the capacities and number of returns to be repaired at the selected RFs. Fuzzy programming approach is used for effectively obtaining a properly efficient solution, which satisfies the decision maker's (DM's) desired aspiration levels for the conflicting objectives of minimising the cost and maximising the sustainable performance of selected RFs. As per our knowledge, an optimisation model for an integrated RL network design focussing on sustainable evaluation and selection of RFs, capacity expansion as well as penalty for under-utilisation of capacities of selected RFs, along with flow allocation decisions has not been considered in the previous studies. Another notable contribution of the present work is that the model is illustrated using a case study of an electronic manufacturing firm in India. The fuzzy decision-making model can be effectively used by SC managers of the firm for configuring a sustainable RL network with conflicting goals.

The rest of the article includes the relevant literature review, the problem definition, and the proposed RL network followed by the proposed methodology. A brief description of the fuzzy programming approach is presented, which is applied to validate the proposed RL model using the data set of a real case study. Furthermore, the results are discussed, and finally, the concluding remarks are provided in the end.

\section{Literature review}

In the last few years, the growing 'take-back' laws are challenging the manufacturing firms to redesign their logistics network to incorporate RL into their network. Although there is a plethora of literature on RL network designing (Darbari et al. 2015:2; Dehghanian \& Mansour 2009:560; Ilgin \& Gupta 2010:567; Kannan et al. 2012:76), most of the studies in the literature have focussed on establishing RL network designs only from a 3PRLP's perspective (Mahmoudzadeh, Mansour \& Karimi 2011a:338; Mahmoudzadeh et al. 2011b:30; Min \& Ko 2008:176), while the OEM's perspective has been not been considered. From the OEM's perspective, there are various strategic, tactical and operational decisions that the OEM must ponder upon, for creating an effective RL network (Aras et al. 2015:325). The strategic choices have long-term significance on the recovery network. These include network design models comprising the location of the CCs (Aras, Aksen \& Tanuğur 2008:1223), inspection centres (Alumur et al. 2012:71), recycling centres (Aras et al. 2015:324), remanufacturing facilities (Diabat, Abdallah \& Henschel 2015:245), et cetera. The second class of decisions are tactical decisions that have a mediumterm impact on RL. These decisions include policies for inventory management of returned products (Zhang 2013:598), transportation decisions (Shaik \& Abdul-Kadir 2013:495), et cetera. Finally, there are operational decisions that impact the $\mathrm{RL}$ on a short-term basis. These include decisions pertaining to the flow of products, components and material across various facilities of the network (Darbari, Agarwal \& Jha 2016:791).

Deciding on the locations of warehouses, CCs and repair facilities are key aspects of the strategic plan of reverse SC configuration. However, the decisions regarding the facility locations must not be made in isolation but must be integrated within the RL network design to achieve an efficient recovery system. Many researchers have focussed on developing mathematical models for configuring logistics network design integrating facility location decisions and RL functions (Achillas et al. 2010a:2594; Alumur et al. 2012:67, 2015:419; Assavapokee \& Wongthatsanekorn 2012:129; Gomes, BarbosaPovoa \& Novais 2011:1645; Xianfeng, Jianwei \& Meilian 2010:403; Zhang \& Lee 2013:1348). Most previous studies have 
focussed only on economic considerations and there is a lack of research addressing social and environmental issues in facility location problems within the context of RL network design (Abdessalem, Hadj-Alouane \& Riopel 2012:139; Kim \& Lee 2013:1132; Queiruga et al. 2008:182; Tari \& Alumur 2014:157). Very few studies have considered factors of evaluation, which address all three dimensions of sustainability (Achillas et al. 2010b:870; Temur, Kaya \& Kahraman 2014:591; Zhou \& Zhou 2015:61). Although a lot of research has been done on the aspects of facility location selection within the domain of RL network designing, selection of CCs as RFs based on all three indicators of sustainability, particularly in the context of the Indian electronics sector as done in the present article, has been missing in the literature. In addition, the novelty of the present research work also lies in developing an integrated RL optimisation model, which can capture a trade-off between the conflicting objectives of minimising cost and maximising the sustainable performance of the RFs, while making crucial facility location and flow allocation decisions.

\section{Problem definition}

The present RL network of the company consists of retail zones each having a designated CC, which is the collection point for the entire zone. All the returns consolidated at the CCs are collected by a 3PRLP, which pays a fixed price for all the returns irrespective of the quality. The 3PRLP then takes responsibility of the returns and the company's legal duty of handling its returns is fulfilled. Because of customer pressure, market competence and environmental consciousness, the company aims to act more responsibly and design its RL network so as to take control of the processes independently or jointly with service providers. To realise the potential of huge economic benefits from the sale of secondary products, the company plans to perform the processes of collection, inspection, repairing and redistribution to secondary markets (SM) on its own. Strategic decisions are to be made regarding how many new RFs are required and where they should be located. Official dismantlers and recyclers must manage the process of dismantling, recycling and proper disposal as per the laws mandated by the government (Borthakur \& Singh 2012:360). Therefore, these activities are outsourced to 3PRLPs. The company in association with non-governmental organisations (NGOs) seeks to play an influential role in providing opportunities to the lesser privileged section of the society. As a consequence, it plans to donate some of its returns that are in reasonable good working condition to those in need through the NGO. This initiative is to be carried out at the RFs. In view of this, a fuzzy decision-making model is proposed for developing an economically, environmentally and socially sound RL network, which addresses the following concerns:

- Quick collection and redistribution to ensure a steady flow of returns across every facility.

- Choosing suitable RFs, with adequate infrastructure, to carry out the repairing, refurbishing and repacking processes.
- The location, number and capacity of RFs are determined within budgetary limits.

- The RL network has positive environmental as well as social significance.

\section{Proposed reverse logistics network}

The proposed RL network designed to address the above concerns consists of CCs, an integrated dismantling centre (DMC), a SM, a scrap yard and an NGO as illustrated in Figure 1. Because all the recovery options were previously managed by 3PRLP, the company was losing out on the revenue generated from selling the repaired products at the SM, which is a substantial amount. In this regard, the company plans to take charge of the repairing of products. Repairing of electronic returns requires replacement and refurbishment of parts to renovate the product so that it can be easily reused. It is a manual process that can be handled by the trained staff of the company. Opening new RFs for repairing and refurbishing is not required as the process can be easily managed manually by a team of skilled technicians and can be carried at CCs with proper expansion of space and infrastructure. However, because the number of returns to be repaired and refurbished is not significantly large, not all CCs are to function as RFs. The selection of a CC as RF is to be made based on a number of sustainable factors and requires a careful analysis of the existing scenario and future plans.

The flow of returns of the above network begins with the collection and inspection process at CCs. The initial level of inspection determines the buyback value based on the working state, type and age of the model. The returns are then segregated for repair, donation to an NGO, dismantling or sent to the scrap yard. The returns not fit to be reused or donated are to be disassembled for recovery of parts and materials and sent to the DMC for part recovery or to the scrap yard for material recovery or safe disposal. The DMC is third-party owned, and the returns to be dismantled are collected by the 3PRLP from the CCs. Legal recyclers who take care of the discarded returns and parts for valuable material recovery and safe disposal manage the scrap yard.

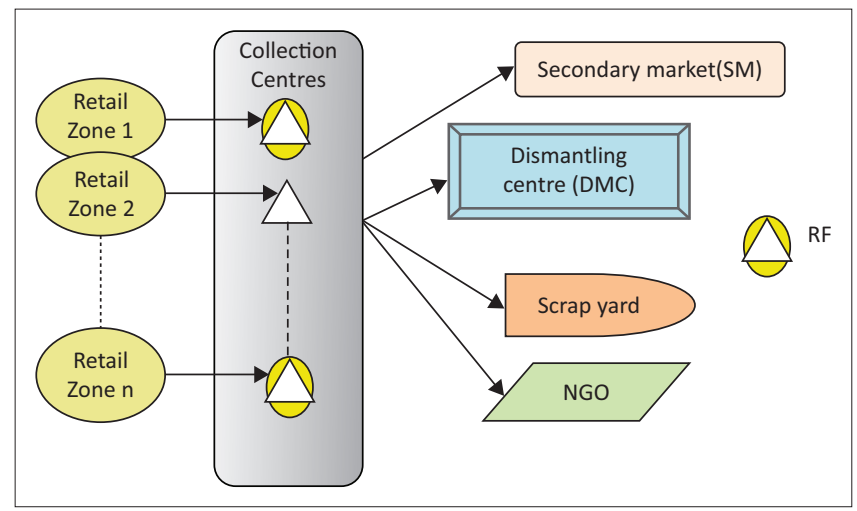

FIGURE 1: Reverse logistics network design. 


\section{Proposed methodology}

The methodology adopted for configuring the proposed network can be outlined as follows:

- For selection of CCs as RFs, the CCs are evaluated under a comprehensive list of sustainable criteria using the AHP-COPRAS method. The output of the AHP-COPRAS method is the utility of each CC that represents the relative performance of one $\mathrm{CC}$ over the other.

- A bi-objective fuzzy mathematical model is formulated, which selects the CC to function as RF, determines the level of capacity expansion and allocates each CC to exactly one $\mathrm{RF}$ for sending the returns to be repaired. The key decisions are made while capturing a trade-off between the fuzzy objectives of minimising cost of the network and maximising the sustainable performance of the RFs.

\section{Integrated Analytical Hierarchical Process - Complex Proportional Assessment application for the evaluation of collection centres}

The decision regarding the selection of CCs to function as RFs is of strategic importance and has major environmental and social significance because of the expansion of space, job creation and the community development initiatives undertaken.

For this reason, the following sustainable quantitative and qualitative criteria are chosen after an extensive literature survey and intensive interaction with the decision makers: Distance from DMC and centre of gravity (C1), Running cost (C2), Rent Cost (C3), Customer Service Rating (C4), Effectiveness of RL (C5), Environmental Considerations (C6), Technical Qualifications (C7) and Scope for Community Developments (C8) (Ertuğrul 2011:734; Liu, Chan \& Chung 2011:430; Pochampally, Nukala \& Gupta 2008:87; Rezaeiniya, Zolfani \& Zavadskas 2012:188; Yang et al. 2008).

The evaluation process based on the above tangible and intangible criteria is a complex and time-consuming group decision-making problem and an integrated MCDM is proposed, which combines the efficiencies of AHP and COPRAS method. Firstly, the weights of the criteria are determined through AHP (Saaty 1987:70) and then COPRAS (Zavadskas et al. 2008:88) is employed to evaluate the alternatives based on mutually conflicting criteria along with the derived criteria weights. The procedure measures the performance of the alternatives (CCs) in terms of their relative preferences and utility.

The procedure for applying the AHP-COPRAS method is as follows: Suppose there are $n$ alternatives and $m$ criteria. We first evaluate the importance of $w_{j}^{\prime}$ s (in terms of weights) of the criteria using AHP. Pairwise comparisons of the $m$ criteria are done by $k$ DMs using a nominal scale of $1-9(1,3$, 5,7 and 9 represent equal, moderate, strong, very strong and absolutely essential, respectively, and 2, 4, 6 and 8 are intermediate values). We generate $k$ matrices ( $m x m$ ) with the $(r, s)^{\text {th }}$ element representing the relative importance of criteria $r$ over criteria $s$. The average of these matrices yields the final decision matrix A whose consistency ratio is:
$C R=\frac{C I}{R I}$

where CI is the consistency index, which is calculated as follows:

$C I=\frac{\left(\lambda_{\max }-m\right)}{(m-1)}$,

where $\lambda_{\max }$ is the largest eigenvalue of $\mathrm{A}$.

Because there are eight criteria of evaluation, $m=8$. The value of RI is 1.40 as obtained from the study by Saaty (1987:71). A value of $\mathrm{CR}$ less than 0.01 is acceptable. The eigenvector (priority vector) $w=\left(w_{1}, w_{2}, \ldots, w_{m}\right)$ of $\mathrm{A}$ is calculated using the following equation:

$A w=\lambda_{\max } w$

The priority vector is the weighted vector, which represents the importance weights of the criteria.

We now proceed on to evaluate the performance of the alternatives subject to the criteria by applying the following steps of the COPRAS method (Gadakh 2014:25).

Step 1: Formulate the $n x m$ decision matrix $X$. Let all the columns corresponding to beneficial criteria (the more the better) be arranged before those corresponding to nonbeneficial criteria (lesser the better). The matrix $\mathrm{X}$ is then:

$X=\left[x_{i j}\right]_{n X m}=\left[\begin{array}{cccccc}x_{11} & x_{12} & \cdot & . & . & x_{1 m} \\ x_{21} & x_{22} & \cdot & . & \cdot & x_{2 m} \\ \cdot & \cdot & \cdot & \cdot \\ \cdot & \cdot & \cdot & \cdot \\ \cdot & \cdot & & \cdot & \cdot \\ x_{n 1} & x_{n 2} & \cdot & \cdot & . & x_{n m}\end{array}\right]$

[Eqn 2]

where $x_{i j}$ is the value of criterion $j$ of alternative $i$. The values are derived from the quantitative data provided by the company. In the case of criteria for which values cannot be quantified, alternatives are evaluated with respect to that criteria using AHP and the column vector is the derived priority vector from the AHP calculations.

Step 2: Derive the normalised decision matrix $Y$ as follows:

$Y=\left[y_{i j}\right]$ where $y_{i j}=\frac{x_{i j}}{\sum_{i} x_{i j}}$

Step 3: Construct the weighted normalised decision matrix:

$D=\left[d_{i j}\right]$

where $d_{i j}=y_{i j} w_{j}$ and $w_{j}$ is the criterion weight (derived using the AHP). 
Step 4: For each alternative $i$, calculate the sums of values $d_{i j}$ 's for all beneficial criteria and the sums of values $d_{i j}$ 's for all non-beneficial criteria using the following equations:

$$
\begin{aligned}
& S_{i}^{+}=\sum_{j \in \text { Beneficial }} d_{i j} \\
& S_{i}^{-}=\sum_{j \in \text { non-beneficial }} d_{i j}
\end{aligned}
$$

Step 5: The relative weight $Q_{i}$ is determined using the following equation:

$$
Q_{i}=S_{i}^{+}+\frac{\sum_{i} S_{i}^{-}}{S_{i}^{-} \sum_{i} \frac{1}{S_{i}^{-}}}
$$

Greater values of $Q_{i}$ signify higher priority.

Step 6: The utility $U_{i}$ of each alternative, a percentage value between 0 and 100, shows by what percentage one alternative performs better than the other and is computed by comparing the priorities of alternatives with the best one as shown below:

$U_{i}=\frac{Q_{i}}{Q_{\max }} * 100 \%$

[Eqn 7]

where $Q_{\max }=\max \left\{Q_{i}: i \in I\right\}$

\section{Bi-objective fuzzy model formulation}

A fuzzy optimisation model is formulated for configuring the proposed RL network using the assumptions and notations given below.

\section{Assumptions}

- Locations and capacities of the CCs and DMC are known.

- The demand of the SM is high.

- The cost parameters are deterministic.

- Activities outsourced to 3PRLP do not incur any extra cost to the company.

\section{Notations}

Sets:

- $i$ : set of CCs

- $p:$ dismantling centre.

Parameters:

- $c^{\text {trans }}$ cost of transportation (per km)

- $c_{i}^{\text {fixed }}$ fixed cost of expansion of $i$ th CC

- $c_{i}^{\exp } \quad$ variable cost of expansion of $i$ th CC(per square feet)

- $c^{\text {rep }}$ per unit cost of repair

- $c^{\text {penalty }}$ penalty cost

- $c^{\text {budget }}$ total budget for expansion

- $d_{i j}$ distance between CCs (in km)

- $\quad M_{i} \quad$ capacity of $i$ th CC(in units of returns)

- $M_{i}^{l} \quad$ lower limit of capacity of the $i$ th CC

- $M_{i}^{h} \quad$ upper limit of capacity of the $i$ th CC
- $u_{i} \quad$ utility of the $i$ th CC as obtained from hybrid AHPCOPRAS

- $u_{\min }$ minimum threshold of utility

- $k$ maximum number of repair facilities

- $\alpha_{j} \quad$ percentage of products to be repaired

- $r_{i}^{e n v}$ environmental criteria of the $i$ th CC

- $r_{\text {threshold }}^{\text {env }}$ minimum threshold for environmental criteria

- $r_{i}^{\text {social }}$ social criteria of the $i$ th CC

- $r_{\text {threshold }}^{\text {social }}$ minimum threshold for the social criteria

- $X_{j} \quad$ total number of returns at the $j$ th CC.

Decision variables:

- $B_{i j} \quad$ a binary variable whose value is 1 if the $j$ th CC sends its returns to the $i$ th selected CC, 0 otherwise

- $A_{i}$ a binary variable whose value is 1 if the CC is selected for expansion, 0 otherwise

- $X_{i}^{\text {rep }}$ the number of products repaired at the $i$ th CC

- $X_{\text {total }}^{\text {rep }}$ total number of products repaired

Fuzzy multi-objective programming problem

$$
\begin{aligned}
\operatorname{Min} f_{1} \cong & \sum_{i} \sum_{j} c^{\text {trans }} d_{i j} B_{i j}+\sum_{i} c^{\text {trans }} d_{i p} A_{i}+\sum_{i} X_{i}^{\text {rep }} c^{\text {rep }} \\
& \sum_{i}\left[c_{i}^{\text {fxed }}+\left(M_{i}-M_{i}^{l}\right) c_{i}^{\text {exp }}+c^{\text {penalty }}\left(M_{i}^{h}-M_{i}\right)\right] A_{i}
\end{aligned}
$$

[Eqn 8]

$\operatorname{Max} f_{2} \cong \sum_{i} u_{i} A_{i}$

[Eqn 9]

The first objective of the fuzzy multi-objective programming (FMOP) problem minimises the total cost of the network encompassing the cost of transportation (from CCs to RF and from RFs to DMC), cost of repair, fixed and variable cost of expansion and penalty cost for under-utilisation of capacities of selected RFs. As the focus is largely on minimising costs, the profit from selling of repaired products is not considered in the objective. The second objective maximises the overall utility of the CCs selected for expansion, which ensures that CCs with better performance value are chosen.

Constraints:

$\sum A_{i} \geq 1$

[Eqn 10]

$\sum A_{i} \leq k$

[Eqn 11]

$B_{i j}=\mathrm{A}_{i} \forall i=j$

[Eqn 12]

$\sum_{i} \sum_{j} B_{i j}=I$

$\sum_{i} B_{i j}=1 \forall j$

[Eqn 14]

$M_{i} \leq M_{i}^{h} \quad \forall i$

[Eqn 15]

$M_{i} \geq M_{i}^{l} \quad \forall i$

[Eqn 16]

$X_{\text {total }}^{\text {rep }}=\sum_{j} \alpha_{j} X_{j}$

[Eqn 17] 
$\sum_{i} X_{i}^{\text {rep }}=X_{\text {total }}^{\text {rep }}$

[Eqn 18]

$X_{i}^{r e p}=\sum_{j} \alpha_{j} X_{j} B_{i j} \quad \forall i$

[Eqn 19]

$X_{i}^{\text {rep }}<=M_{i} A_{i} \quad \forall i$

[Eqn 20]

$\sum_{i}\left[c_{i}^{\text {fred }}+\left(M_{i}-M_{i}^{l}\right) c_{i}^{\text {exp }}\right] A_{i} \leq c^{\text {budget }}$

[Eqn 21]

$r_{i}^{e n v} A_{i} \leq r_{\text {threshold }}^{\text {env }} \quad \forall i$

$r_{i}^{\text {social }} A_{i} \leq r_{\text {threshold }}^{\text {social }} \quad \forall i$

$u_{i} \geq u_{\min } A_{i} \quad \forall i$

[Eqn 24]

$A_{i^{\prime}} B_{i j} \in\{0,1\}$

$X_{i}^{\text {rep }}, X_{\text {total }}^{\text {rep }} \geq 0$ and integer

[Eqn 26]

Equation (10) ensures that at least one CC should be selected for expansion to RF. Equation (11) limits the number of CCs selected for expansion. Equations (12)-(14) determine that each CC is allocated to exactly one RF for sending their returns to be repaired. Equation (15) and (16) give the minimum and maximum scope of expansion of CCs. Equation (17)-(19) ensure that the total number of returns that need to be repaired, calculated as a fraction of the total number of returns, are all sent for repair. Equation (20) ensures that the number of returns sent to each RF must be less than its capacity for expansion (it is zero if the $\mathrm{CC}$ is not selected). Equation (21) is the budgetary constraint, which states that the total fixed and variable cost of expansion should be less than the total budget allocation for expansion. Equation (22), (23) and (24) make sure that the selected CC must satisfy the minimum threshold level for environmental and social criteria and must meet the minimum desired utility value. Equation (25) and (26) ensure the binary restrictions as well as the non-negativity restrictions.

\section{Fuzzy solution approach for multi-objective optimisation}

Fuzzy optimisation approach permits adequate solutions of real-world RL network problems having objectives that are normally fuzzy or imprecise in nature and cannot be quantified by crisp mathematical programming approaches. In the FMOP problem (P1) defined above, we have two conflicting objectives to be optimised simultaneously, and clearly, a trade-off is required between the objectives leading to a compromised solution. The fuzziness in the objectives is considered to provide flexibility to the DMs for choosing a preferred efficient solution.

Fundamental to multi-objective optimisation is the concept of efficient and properly efficient solutions. However, if the goals are fuzzy, the concept is extended to fuzzy efficient and fuzzy, properly efficient solutions, defined in terms of membership functions, instead of objective functions (Jiménez \& Bilbao 2009:2716; Sakawa 2013:7). The corresponding terms are defined below.

\section{Definition 1: Membership function}

We utilise fuzzy set theory (Bellman \& Zadeh 1970:B141) to mathematically represent the fuzzy objectives $f_{1}$ (minimisation) and $f_{2}$ (maximisation) in terms of membership functions as follows:

$\mu_{f_{1}}(x)\left\{\begin{array}{cc}1 & f_{1}(x) \leq f_{1}^{0} \\ \frac{f_{1}^{*}-f_{1}(x)}{f_{1}^{*}-f_{1}^{0}} & f_{1}^{0}<f_{1}(x) \leq f_{1}^{*} \\ 0 & f_{1}(x)>f_{1}^{*}\end{array}\right.$

[Eqn 27]

$\mu_{f_{2}}(x)=\left\{\begin{array}{cc}1 & f_{2}(x) \geq f_{2}^{0} \\ \frac{f_{2}(x)-f_{2}^{*}}{f_{2}^{0}-f_{2}^{*}} & f_{2}^{*}<f_{1}(x) \leq f_{2}^{0} \\ 0 & f_{1}(x)<f_{2}^{*}\end{array}\right.$

Where $f_{i}^{0}$ and $f_{i}^{*}$ represent the aspiration and tolerance values of the $i$ th goal. These values can be specified by the DM or can also be chosen by solving the two single-objective problems under system constraints (1)-(17) $\left(f_{i}^{0}\right.$ is taken as the best possible value and $f_{i}^{*}$ is the worst possible value obtained of the $i$ th goal).

\section{Definition 2: Fuzzy efficient solution}

$x^{*} \in \mathrm{S}$ is a fuzzy efficient solution of (P1) if there does not exist any $x \in S$ such that $\mu_{f_{i}}\left(x^{*}\right) \leq \mu_{f_{i}}(x) \forall \mathrm{i}=1,2$ and $\mu_{f_{j}}\left(x^{*}\right)<\mu_{f_{j}}(x)$ for at least one $j$.

\section{Definition 3: Fuzzy, properly efficient solution}

A fuzzy efficient solution $x^{*}$ of (P1) is said to be a fuzzy, properly efficient solution if there exists a scalar $M>0$ such that for each $x \in S$ :

$\mu_{f_{i}}(x)-\mu_{f_{i}}\left(x^{*}\right) \leq \mathrm{M}\left(\mu_{f_{r}}\left(x^{*}\right)-\mu_{f_{r}}(x)\right)$,

with $\mu_{f_{r}}\left(x^{*}\right)>\mu_{f_{r}}(x)$ for some $r$ and $\mu_{f_{i}}(x)>\mu_{f_{i}}\left(x^{*}\right)$ for each $i$

[Eqn 28]

Solution approach for obtaining a fuzzy, properly efficient solution

Using Zimmermann's max-min operator approach (Zimmermann 1978:49), problem (P1) can be transformed into the following equivalent crisp single-objective linear programming problem:

Maximise $\alpha$

subject to

$\mu_{f_{1}}(x) \geq \alpha$

[Eqn 29]

$\mu_{f_{2}}(x) \geq \alpha$

$x \in S, \alpha \in[0,1]$

The auxiliary variable $\alpha$ represents the degree of satisfaction to which the objective is satisfied. 
The max-min approach used in (P2) ensures that if it has a unique optimal solution, then it is a fuzzy efficient solution of (P1). However, in the case of multiple optimal solutions, not every optimal solution of (P2) is a fuzzy efficient solution of (P1). To overcome the issue, the following weighted problem (P3) can be formulated in an endeavour to finding a fuzzy efficient solution (Tiwari, Dharmar \& Rao1987:30):

$$
\begin{aligned}
& \text { Maximise } w_{1} \alpha_{1}+w_{2} \alpha_{2} \\
& \text { subject to } \\
& \mu_{f_{1}}(x) \geq \alpha_{1} \\
& \mu_{f_{2}}(x) \geq \alpha_{2} \\
& x \in S, \alpha_{1}, \alpha_{2} \in[0,1], w_{1}+w_{2}=1
\end{aligned}
$$

where $w_{1}$ and $w_{2}$ are weights assigned to $f_{1}$ and $f_{2}$, while $\alpha_{1}$ and $\alpha_{2}$ represent their achievement levels, respectively.

An optimal solution of (P3) is a fuzzy, properly efficient solution of (P1) (Refer Lemma 1 in Appendix 1).

Although the objectives with more importance are achieved at higher levels using the additive model, the ratio of the levels is not close to the ratio of that of the weights. This is desirable to truly preserve the relative importance of the objectives, defined by the DMs in terms of the weights.

Hence, in this article, the following weighted max-min model (P4) proposed by Lin (2004:411) is utilised, which finds 'an optimal solution within the feasible area such that the ratio of the achieved levels of the objectives $\left(w_{1} \alpha / w_{2} \alpha\right)^{\prime}$ is the same as the ratio of the weights $\left(w_{1} / w_{2}\right)^{\prime}$ :

\section{Maximise $\alpha$}

subject to

$\mu_{f_{1}}(x) \geq w_{1} \alpha$

$\mu_{f_{2}}(x) \geq w_{2} \alpha$

$x \in S, \alpha \in[0,1], w_{1}+w_{2}=1$

An optimal solution of (P4) yields a fuzzy, properly efficient solution of the original FMOP problem (P1).

The fuzzy solution procedure discussed above for solving the proposed model is integrated into the following solution algorithm:

\section{Fuzzy solution algorithm}

Step 1: The original FMOP problem is formulated.

Step 2: The aspiration and tolerance levels are either specified by the DMs or can be obtained by solving the two singleobjective programming problems. The corresponding linear membership functions are defined for the fuzzy objectives.

Step 3: The weights for the objective functions are taken as per DMs preferences.
Step 4: An equivalent crisp scalar problem (P4) of (P1) is formulated.

Step 5: An optimal solution of (P4) generates the fuzzy, properly efficient solution of (P1).

The following numerical example illustrates how the proposed model can be solved using the above solution algorithm.

\section{Numerical example}

The case study considered in here is of an electronics manufacturing company located in Delhi National Capital Region, India. The company has 8 CCs located in the region that carry out the initial collection as well as inspection of the returned products. The DMC is situated at Mayapuri, and the CCs are located at East of Kailash (A1), Vaishalli (A2), Noida (A3), Dwarka (A4), Vasant Kunj (A5), Sushant Lok (A6), Karol Bagh (A7) and Model Town (A8) as shown in Figure 2. A team of company stakeholders are assigned the task of evaluation of the expansion of the CCs to incorporate the repairing, refurbishing and repackaging processes.

For the purpose of evaluation, the relative importance of the criteria is derived using the AHP as shown in Table 1. The components of the eigenvector represent the weights of the criteria. Non-beneficial criteria are marked as (-) and the beneficial criteria are marked as $(+)$.

These weights are utilised in the initial decision matrix of the COPRAS method as shown by Table 2 . The columns of the matrix correspond to the performance of the alternatives (CCs) for each criterion. The column for criteria $\mathrm{C} 1$ indicates the distance calculated as the sum of the distance of CC from the DMC and its distance from the centre of gravity of all CCs (Values from Table 3 are used for the calculation). Column C2 is the running cost, which is the monthly cost for carrying the operations at CC. C3 is the per square feet rental cost of CC. C4-customer service level and C7-technological capability are measured using a scale of 1-10 where higher values signify higher performance. In the absence of quantitative data for criteria $\mathrm{C} 5, \mathrm{C} 6$ and $\mathrm{C} 8$, the $\mathrm{AHP}$ is used for comparing the alternatives for each criterion using the derived priority vectors.

Following steps 1-7 of the AHP-COPRAS method, the weighted normalised matrix is derived and the priority value $Q i$ and utility $U i$ are computed. Table 4 represents the final matrix of calculation.

The inference drawn from Table 4 is that A4 is the best choice among the alternatives. A7 is the second best and third and fourth choices are A8 and A2. The last column represents the utility of each $\mathrm{CC}$, which reflects the relative sustainable performance of each CC. This column vector is used as an input parameter for solving the proposed mathematical model. 


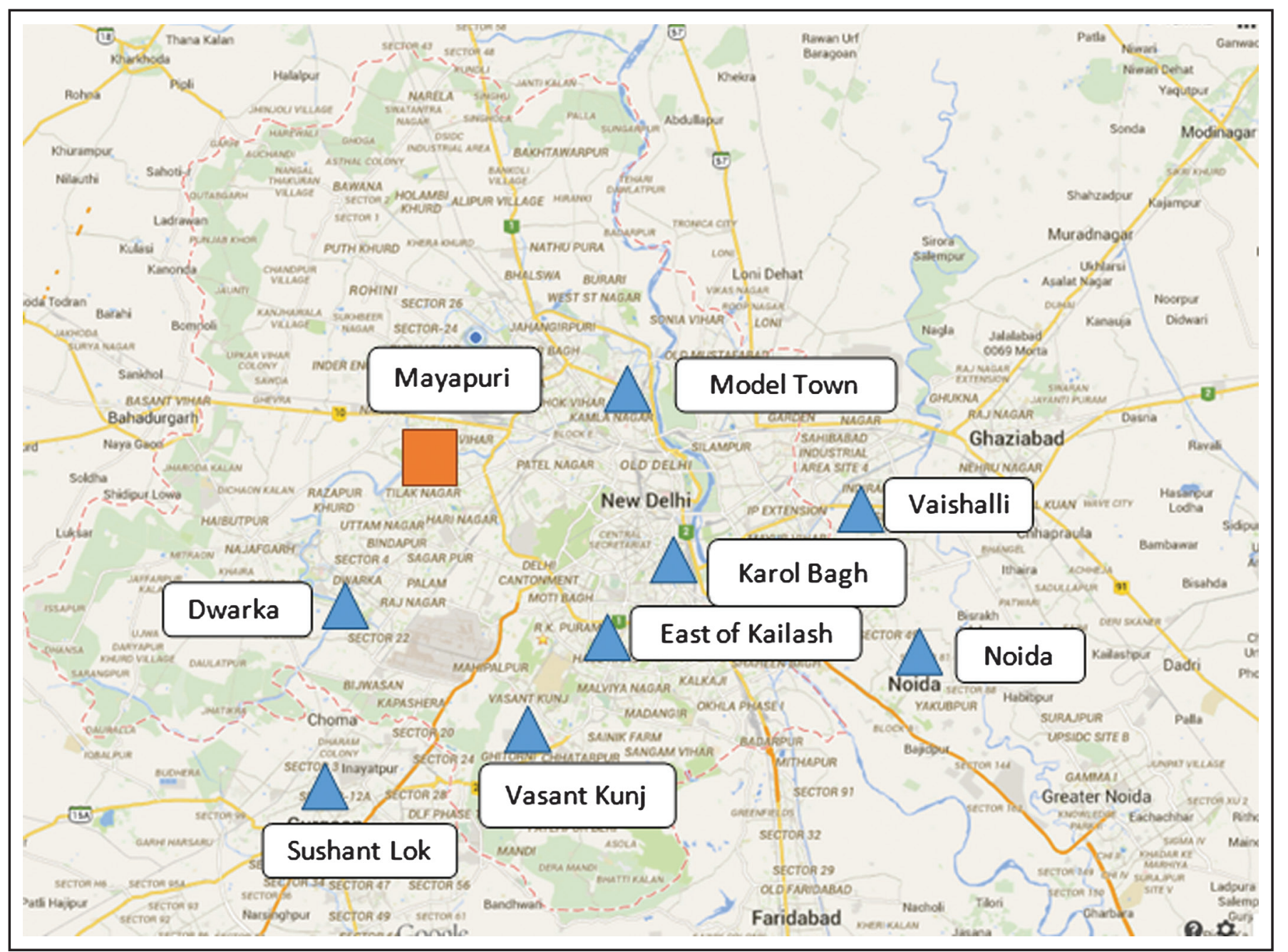

Source: Adapted from Google Maps, n.d., Delhi, viewed n.d., from https://www.google.co.in/maps/place/Delhi FIGURE 2: Location of collection centres.

TABLE 1: Weights of criteria.

\begin{tabular}{|c|c|c|c|c|c|c|c|c|c|}
\hline Goal & C1 & $\mathrm{C2}$ & $\mathrm{C3}^{-}$ & $\mathrm{C4}^{+}$ & $\mathrm{C5}^{+}$ & $\mathrm{C6}^{+}$ & $\mathrm{C7}^{+}$ & $\mathrm{CB}^{+}$ & Eigenvector \\
\hline $\mathrm{C} 1$ & 1.00 & 1.00 & 0.50 & 3.00 & 1.00 & 1.00 & 0.50 & 2.00 & 0.120 \\
\hline $\mathrm{C} 2$ & 1.00 & 1.00 & 0.50 & 2.00 & 0.50 & 0.33 & 0.50 & 2.00 & 0.090 \\
\hline C3 & 2.00 & 2.00 & 1.00 & 3.00 & 1.00 & 2.00 & 2.00 & 2.00 & 0.200 \\
\hline C4 & 0.33 & 0.50 & 0.33 & 1.00 & 0.50 & 0.50 & 0.50 & 1.00 & 0.060 \\
\hline C5 & 1.00 & 2.00 & 1.00 & 2.00 & 1.00 & 1.00 & 1.00 & 2.00 & 0.150 \\
\hline C6 & 1.00 & 3.00 & 0.50 & 2.00 & 1.00 & 1.00 & 2.00 & 3.00 & 0.160 \\
\hline $\mathrm{C7}$ & 2.00 & 2.00 & 0.50 & 2.00 & 1.00 & 0.50 & 1.00 & 2.00 & 0.130 \\
\hline $\mathrm{C} 8$ & 0.50 & 0.50 & 0.50 & 1.00 & 0.50 & 0.33 & 0.50 & 1.00 & 0.065 \\
\hline
\end{tabular}

TABLE 2: Initial decision matrix.

\begin{tabular}{|c|c|c|c|c|c|c|c|c|}
\hline Alternatives & C1 & $\mathrm{C2}$ & $\mathrm{C3}^{-}$ & $\mathrm{C4}^{+}$ & $\mathrm{C5}^{+}$ & $\mathrm{C6}^{+}$ & $\mathrm{C7}^{+}$ & $\mathrm{C}^{+}$ \\
\hline$\overline{\mathrm{A} 1}$ & 64.8 & 4000 & 110 & 9 & 0.202117 & 0.058518 & 9 & 0.048296 \\
\hline A2 & 57.0 & 3000 & 60 & 4 & 0.058200 & 0.203224 & 4 & 0.245266 \\
\hline A3 & 63.8 & 3000 & 60 & 7 & 0.074075 & 0.081324 & 6 & 0.138629 \\
\hline A4 & 66.5 & 2500 & 35 & 5 & 0.083738 & 0.221617 & 5 & 0.186362 \\
\hline A5 & 63.5 & 4000 & 100 & 8 & 0.161560 & 0.120989 & 9 & 0.131778 \\
\hline A6 & 85.5 & 3000 & 65 & 7 & 0.104758 & 0.061716 & 8 & 0.096593 \\
\hline A7 & 51.0 & 3500 & 70 & 9 & 0.195223 & 0.120837 & 9 & 0.081224 \\
\hline $\mathrm{A} 8$ & 50.5 & 3000 & 60 & 8 & 0.120330 & 0.131774 & 8 & 0.071852 \\
\hline
\end{tabular}

The data set provided by the company is as follows: The fixed cost of expansion of each CC is Rs. 150 000, Rs. 100 000, Rs. 120 000, Rs. 100 000, Rs. 110 000, Rs. 130 000, Rs.
130000 and Rs. 110 000, respectively, while the per square foot cost of expansion is Rs. 110, Rs. 60, Rs. 60, Rs. 35, Rs. 100, Rs. 65, Rs. 70 and Rs. 60, respectively, for each CC. 
TABLE 3: Distance between collection centres.

\begin{tabular}{|c|c|c|c|c|c|c|c|c|}
\hline$d_{i j}$ & i1 & i2 & i3 & i4 & i5 & i6 & i7 & i8 \\
\hline $\mathrm{i1}$ & 0.0 & 8.0 & 4.0 & 11.0 & 6.0 & 9.7 & 7.0 & 9.0 \\
\hline i2 & 8.0 & 0.0 & 4.5 & 16.9 & 12.8 & 17.7 & 9.5 & 9.0 \\
\hline i3 & 4.0 & 4.5 & 0.0 & 15.0 & 10.0 & 13.9 & 9.0 & 10.1 \\
\hline i4 & 11.0 & 16.9 & 15.0 & 0.0 & 5.3 & 8.3 & 7.9 & 10.4 \\
\hline i5 & 6.0 & 12.8 & 10.0 & 5.3 & 0.0 & 6.1 & 6.0 & 9.2 \\
\hline i6 & 9.7 & 17.7 & 13.9 & 8.3 & 6.1 & 0.0 & 12.1 & 15.3 \\
\hline i7 & 7.2 & 9.5 & 9.0 & 7.9 & 6.0 & 12.1 & 0.0 & 3.1 \\
\hline i8 & 9.5 & 9.0 & 10.1 & 10.4 & 9.2 & 15.3 & 3.1 & 0.0 \\
\hline
\end{tabular}

TABLE 4: Normalised weighted decision matrix

\begin{tabular}{|c|c|c|c|c|c|c|c|c|c|c|c|c|}
\hline Weights & 0.122 & 0.092 & 0.205 & 0.062 & 0.150 & 0.166 & 0.138 & 0.065 & $\begin{array}{c}\text { Sum of beneficiary } \\
\text { attributes }\end{array}$ & $\begin{array}{c}\text { Sum of non-beneficiary } \\
\text { attributes }\end{array}$ & $\begin{array}{c}\text { Relative significance } \\
\text { value }\end{array}$ & Utility \\
\hline -Alternatives & $\mathrm{C} 1^{-}$ & $\mathrm{C} 2$ & $\mathrm{C} 3^{-}$ & $\mathrm{C}^{+}$ & $\mathrm{C}^{+}$ & $\mathrm{C}^{+}$ & $\mathrm{C}^{+}$ & $\mathrm{C}^{+}$ & $\mathrm{Sj}^{+}$ & $\mathrm{Sj}^{-}$ & $Q_{j}$ & $\mathrm{Ui}$ \\
\hline $\mathrm{A} 1$ & 0.016 & 0.014 & 0.040 & 0.010 & 0.030 & 0.010 & 0.021 & 0.003 & 0.074 & 0.070 & 0.112 & 75.3 \\
\hline $\mathrm{A} 3$ & 0.015 & 0.011 & 0.022 & 0.008 & 0.011 & 0.014 & 0.014 & 0.009 & 0.055 & 0.048 & 0.111 & 74.3 \\
\hline A4 & 0.016 & 0.009 & 0.013 & 0.005 & 0.013 & 0.037 & 0.012 & 0.012 & 0.078 & 0.037 & 0.149 & 100 \\
\hline A5 & 0.015 & 0.014 & 0.037 & 0.009 & 0.024 & 0.020 & 0.021 & 0.009 & 0.083 & 0.066 & 0.123 & 82.6 \\
\hline A7 & 0.012 & 0.012 & 0.026 & 0.010 & 0.029 & 0.020 & 0.021 & 0.005 & 0.085 & 0.050 & 0.138 & 92.9 \\
\hline A8 & 0.012 & 0.011 & 0.022 & 0.009 & 0.018 & 0.022 & 0.019 & 0.005 & 0.072 & 0.044 & 0.131 & 88.2 \\
\hline
\end{tabular}

The repair cost per unit product at each CC is Rs. 130. The per kilometre transportation cost is Rs. 10, the penalty cost per unit is Rs. 20 and the total budget for expansion is Rs. 450 000. The lower limits for the capacity of the CCs are $180,250,150,250,180,170,185$ and 240, respectively, with the upper limits set as 350, 200, 400, 250, 250, 300 and 260, respectively. The distance of each CC from the dismantling unit at Mayapuri (in $\mathrm{km}$ ) is 9.4, 13.5, 12.4, 4, 5, 10.5, 4 and 6.4 , respectively.

\section{Results and discussion Outline of the results}

The fuzzy bi-objective model proposed in the study aims at attaining RL network design in which strategic decisions of evaluation and selection of CCs as RFs and their capacity expansion and operational decision of determining the amount of returns to be repaired are integrated. While doing so, the model seeks for a trade-off between the overall cost of the network and the sustainable performance of the selected CCs. Firstly, to understand the nature of conflict between the objectives, the bi-objective problem is first solved as two separate problems using Lingo 11.0, utilising the above data set. The minimum threshold of utility is taken as $70 \%$ and at most, three RFs can be opened. The company wants to eliminate the option of selecting CCs with low environmental and social performance; therefore, the minimum threshold for environmental criteria as well as social criteria is taken as 7. Solving for objective 1 , which is the cost objective, the model yields a cost of Rs. 1665790 and total utility value of 261.22. The CCs selected for expansion are A2, A3 and A4 and the expansion budget utilisation is Rs. 422200 with a penalty cost of Rs. 21000 . To optimise the cost objective, the model has opted for CCs with lower expansion costs and compromised on their sustainable performance.
Maximisation of the second objective leads to a different result. The total utility value of 281.165 is attained at the cost of Rs. 2088840 with A4, A7 and A8 selected as RFs. The selected CCs rank first, second and third in the evaluation process and incur a higher cost of expansion. The cost of Rs. 427900 is required for expansion, bearing a penalty cost of Rs. 23 000. The two single-objective models clearly show the conflict between the goals. This clearly justifies the use of fuzzy programming approach for providing flexibility to the DMs in explicitly adjusting the target values and tolerance levels of the goals. A compromised solution is arrived by developing Lingo code for problem (P4) and by defining appropriate membership functions using the target and tolerance values for the goals. The weights assigned by the DMs are $w_{1}=0.3$ and $w_{2}=0.7$. The compromised solution obtained at the DM's satisfaction level of 0.829 yields a cost of Rs. 1829847 and an overall utility value of 279.8565. Thus, the fuzzy model has effectively attained a compromised solution as per DM's desirability level. To elaborate upon, we analyse the result findings carefully.

The primary focus of the fuzzy model was to optimally select CCs as RFs and determine the number products to be repaired at each RF, so that a trade-off can be attained between the cost and the sustainable performance of the CCs. Because A4 was the common choice in both cases, it has obviously been selected in the final compromised solution as well. The three CCs selected to function as RFs are Vaishalli (A2), Dwarka (A4) and Karol Bagh (A7), with ranks first, second and fourth. The total number of products to be repaired at these RFs are 334, 310 and 201, respectively; thus, a total of 845 products are repaired. A total budget of Rs. 412600 is needed with a penalty cost of Rs. 4100. At Vaishalli (A2), a total of 334 units from East of Kailash (A1), Vaishalli (A2) and Noida (A3) are repaired; at Dwarka (A4), a total of 310 returns from Dwarka 
(A4), Vasant Kunj (A5) and Sushant Lok (A6) are repaired, whereas at Karol Bagh (A7), a total of 201 returns from Karol Bagh (A7) and Model Town (A8) are repaired. The total budget required for expansion is Rs. 431800 with a penalty cost of Rs. 41000 . The results clearly validate the efficiency of the fuzzy multi-objective optimisation model proposed in the study. The model selects the CCs that can function as RFs, determines the number of products that can be repaired and accordingly the capacity of the selected CC is expanded so the burden of the penalty cost is not much. Although the penalty cost has increased, the budget for expansion has been optimally utilised. The main focus of the firm for designing the RL network is to gain economical value from the returns and enhance their sustainable image. A total of 845 products are repaired, which provide substantial economical gains to the firm. Furthermore, the setting up of RFs based on the sustainable criteria ensures that the firm can attain a sustainable recovery channel for handling its returns.

\section{Practical implications}

The implications drawn from the result findings can be summarised as follows:

- The results reaffirm that electronic manufacturers must not consider adopting RL just as a legal burden and outsource it to 3PRLs, but as an opportunity for collaborating with other reverse SC actors for economic as well as socio-environmental gains.

- The compromised solution attained by the proposed fuzzy model demonstrates that the cost differential for choosing RFs with better environmental and social performance is not significant; therefore, manufacturers must not compromise on the sustainability aspects for facility location decisions.

- Because the proposed model has a general structure, it can be suitably adopted by other industries in modifying their approach towards RL and incorporating environmental and social considerations at the design phase of the RL network.

\section{Conclusion}

Government regulations, customer pressure and market competence are binding factors for electronics manufacturers to design a sustainable recovery model for consumer returns. The manufacturers have also started to realise the potential of $\mathrm{RL}$ and consequently are inclined to handle the returns themselves more effectively and responsibly. In this regard, a bi-objective fuzzy decision-making model is proposed in the study, which can serve as a decision tool for the Indian manufacturers in designing a sustainable RL network for managing end-of-life and end-of-use returns. It is a two-phase model where the first phase involves using a combined AHPCOPRAS methodology for evaluation of the CCs for carrying the repair and refurbishment process. The final selection is done in the second phase with the aid of a mixed integer fuzzy linear programming formulation, which effectively determines the number, location and capacity of RFs, the penalty cost and the number of returns to be repaired at each selected facility. Fuzzy programming approach is used effectively in obtaining a properly efficient solution that satisfies the DM's desired aspiration level for the goals of minimising cost and maximising the sustainable performance of the RFs. The notable feature of the model is the evaluation of CCs under financial, environmental and social considerations and integration of the facility selection decisions with the network designing. This study indicates through the results discussed how an electronic firm in India can earn a sustainable system for their returns in the most cost-efficient way. The study can further elaborate on the nature of collaboration with thirdparty providers and association with NGOs to develop a RL network that clearly defines and determines the role of each party in the functioning of the RL network.

\section{Acknowledgements Competing interests}

The authors declare that they have no financial or personal relationships that may have inappropriately influenced them in writing this article.

\section{Authors' contributions}

All authors have contributed equally to the manuscript.

\section{References}

Abdessalem, M., Hadj-Alouane, A.B. \& Riopel, D., 2012, 'Decision modelling of reverse logistics systems: Selection of recovery operations for end-of-life products', International Journal of Logistics Systems and Management 13(2), 139-161. https://doi.org/10.1504/IJLSM.2012.048933

Achillas, C., Vlachokostas, C., Aidonis, D., Moussiopoulos, N., lakovou, E. \& Banias, G., 2010a, 'Optimising reverse logistics network to support policy-making in the case of electrical and electronic equipment', Waste Management 30(12), 2592-2600. https://doi.org/10.1016/j.wasman.2010.06.022

Achillas, C., Vlachokostas, C., Moussiopoulos, N. \& Banias, G., 2010b, 'Decision support system for the optimal location of electrical and electronic waste treatment plants: A case study in Greece', Waste Management 30(5), 870-879. https://doi.org/-10.1016/j.wasman.2009.11.029

Agarwal, V., Govindan, K., Darbari, J.D. \& Jha, P.C., 2016, 'An optimization mode for sustainable solutions towards implementation of reverse logistics under collaborative framework', International Journal of System Assurance Engineering and Management 7(4), 480-487. https://doi.org/10.1007/s13198-016-0486-3

Alumur, S.A., Kara, B.Y. \& Melo, M.T., 2015, 'Location and logistics', in G. Laporte, S Nickel \& F. Saldanha da Gama (eds.), Location science, pp. 419-441, Springer International Publishing, Cham. https://doi.org/10.1007/978-3-319-13111-5_16

Alumur, S.A., Nickel, S., Saldanha-da-Gama, F. \& Verter, V., 2012, 'Multi-period reverse logistics network design', European Journal of Operational Research 220(1), 67-78. https://doi.org/10.1016/j.ejor.2011.12.045

Aras, N., Aksen, D. \& Tanuğur, A.G., 2008, 'Locating collection centers for incentivedependent returns under a pick-up policy with capacitated vehicles', European Journal of Operational Research 191(3), 1223-1240. https://doi.org/10.1016/j. ejor.2007.08.002

Aras, N., Korugan, A., Büyüközkan, G., Serifoğlu, F.S., Erol, İ. \& Velioğlu, M.N., 2015, 'Locating recycling facilities for IT-based electronic waste in Turkey', Journa of Cleaner Production 105, 324-336. https://doi.org/10.1016/j.jclepro.2015. 02.046

Assavapokee, T. \& Wongthatsanekorn, W., 2012, 'Reverse production system infrastructure design for electronic products in the state of Texas', Computers \& Industrial Engineering 62(1), 129-140. https://doi.org/10.1016/j.cie.2011.09.001

Bellman, R.E. \& Zadeh, L.A., 1970, 'Decision-making in a fuzzy environment', Management Science 17(4), B-141. https://doi.org/10.1287/mnsc.17.-4.B141

Borthakur, A. \& Singh, P., 2012, 'Electronic waste in India: Problems and policies', International Journal of Environmental Sciences 3(1), 353-362.

Chen, L., Olhager, J. \& Tang, O., 2014, 'Manufacturing facility location and sustainability: A literature review and research agenda', International Journal of Production Economics 149, 154-163. https://doi.org/10.1016/j.ijpe.2013. 05.013

Darbari, J.D., Agarwal, V., Chaudhary, K. \& Jha, P.C., 2015, 'Multi-criteria decision approach for a sustainable reverse logistics network under fuzzy environment', in approach for a sustainable reverse logistics network under fuzzy environment', in Management (IEOM), Dubai, United Arab Emirates (UAE), March 03-05, 2015, IEEE, pp. 1-7. https://doi.org/10.1109/IEOM.2015.7093813 
Darbari, J.D., Agarwal, V. \& Jha, P.C., 2016, 'Reverse logistics as a sustainable value proposition for product acquisition', Journal of Information and Optimization proposition for product acquisition, Journal of Information and Optimizati
Sciences 37(5), 791-817. https://doi.org/10.1080/02522667.2016.1191189

Dehghanian, F. \& Mansour, S., 2009, 'Designing sustainable recovery network of endof-life products using genetic algorithm', Resources, Conservation and Recycling 53(10), 559-570. https://doi.org/10.1016/j.resconrec.2009.04.007

Diabat, A., Abdallah, T. \& Henschel, A., 2015, 'A closed-loop location-inventory problem with spare parts consideration', Computers \& Operations Research 54, 245-256. https://doi.org/10.1016/j.ejor.2011.12.045

Dwivedy, M. \& Mittal, R.K., 2012, 'An investigation into e-waste flows in India', Journal of Cleaner Production 37, 229-242. https://doi.org/10.1016/j.jclep-ro.2012.07.017

Ertuğrul, i., 2011, 'Fuzzy group decision making for the selection of facility location' Group Decision and Negotiation 20(6), 725-740. https://doi.org/10.100-7/ s10726-010-9219-1

Gadakh, V.S., 2014, 'Application of complex proportional assessment method for vendor selection', International Journal of Logistics Research and Applications 17(1), 23-34. https://doi.org/10.1080/13675567.2013.836159

Geoffrion, A.M., 1967, Proper efficiency and the theory of vector maximization, Western Management Science Institute, University of California, Los Angeles, CA.

Google Maps, n.d., Delhi, viewed n.d., from https://www.google.co.in/maps/place/ Delhi

Gomes, M.I., Barbosa-Povoa, A.P. \& Novais, A.Q., 2011, 'Modelling a recovery network for WEEE: A case study in Portugal', Waste Management 31(7), 1645-1660. https://doi.org/10.1016/j.wasman.2011.02.023

Ilgin, M.A. \& Gupta, S.M., 2010, 'Environmentally conscious manufacturing and product recovery (ECMPRO): A review of the state of the art', Journal of environmental Management 91(3), 563-591. https://doi.org/10.1016/j.jenvm an.2009.09.037

Jiménez, M. \& Bilbao, A., 2009, 'Pareto-optimal solutions in fuzzy multi-objective linear programming', Fuzzy Sets and Systems 160(18), 2714-2721. https://doi org/1-0.1016/j.fs-s.2008.12.005

Kannan, D., Diabat, A., Alrefaei, M., Govindan, K. \& Yong, G., 2012, 'A carbon footprint based reverse logistics network design model', Resources, conservation and recycling 67, 75-79. https://doi.org/10.1016/j.resconrec.2012.03.005

Khor, K.S., Udin, Z.M., Ramayah, T. \& Hazen, B.T., 2016, 'Reverse logistics in Malaysia: The contingent role of institutional pressure', International Journal of Production Economics 175, 96-108. https://doi.org/10.1016/j.ijpe.2016.01.020

Kim, J.S. \& Lee, D.H., 2013, 'A restricted dynamic model for refuse collection network design in reverse logistics', Computers \& Industrial Engineering 66(4), 1131-1137. https://doi.org/10.1016/j.cie.2013.08.001

Lin, C.C., 2004, 'A weighted max-min model for fuzzy goal programming', Fuzzy Set and Systems 142(3), 407-420. https://doi.org/10.1016/S0165-0114(03)00092-7

Liu, S., Chan, F.T. \& Chung, S.H., 2011, 'A study of distribution center location based on the rough sets and interactive multi-objective fuzzy decision theory', Robotics and Computer-Integrated Manufacturing 27(2), 426-433. https://doi.org/1-0.1016/j. rcim.2010.09.003

Mahmoudzadeh, M., Mansour, S. \& Karimi, B., 2011a, 'A decentralized reverse logistics network for end of life vehicles from third party provider perspective', in 2 nd International Conference on Environmental Science and Technology, Belgrade, Serbia, 28th September-2nd October, 2016, vol. 6, pp. 2338-2342.

Mahmoudzadeh, M., Mansour, S., Shokoohyar, S. \& Karimi, B., 2011b, 'Designing modelling a third party reverse logistics network for end of life vehicles', in 14th International Business Research Conference, Dubai, United Arab Emirates, April 28-30, 2011, vol. 28, p. e30.

Min, H. \& Ko, H.J., 2008, 'The dynamic design of a reverse logistics network from the perspective of third-party logistics service providers', International Journal of
Production Economics 113(1), 176-192. https://doi.org/10.1016/j.ijpe.2007.01.017

Mutha, A. \& Pokharel, S., 2009, 'Strategic network design for reverse logistics and remanufacturing using new and old product modules', Computers \& Industrial Engineering 56(1), 334-346. https://doi.org/10.1016/j.cie.2008.06.006

Pochampally, K.K., Nukala, S. \& Gupta, S.M., 2008, Strategic planning models for reverse and closed-loop supply chains, CRC Press, Boca Raton, FL.
Queiruga, D., Walther, G., Gonzalez-Benito, J. \& Spengler, T., 2008, 'Evaluation of sites for the location of WEEE recycling plants in Spain', Waste Management 28(1) 181-190. https://doi.org/10.1016/j.wasman.2006.11.001

Ravi, V. \& Shankar, R., 2015, 'Survey of reverse logistics practices in manufacturing industries: An Indian context', Benchmarking: An International Journal 22(5), 874-899. https://doi.org/10.1108/BIJ-06-2013-0066

Rezaeiniya, N., Zolfani, S.H. \& Zavadskas, E.K., 2012, 'Greenhouse locating based on ANP-COPRAS-G methods-an empirical study based on Iran', International Journal of Strategic Property Management 16(2), 188-200. https://doi.org/10.3846/1648 715X.2012.686459

Saaty, R.W., 1987, 'The analytic hierarchy process - What it is and how it is used' Mathematical Modelling 9(3), 161-176. https://doi.org/10.1016/0270-0255(87) 90473-8

Sakawa, M., 2013, Fuzzy sets and interactive multiobjective optimization, Springer Science \& Business Media, New York.

Shaik, M.N. \& Abdul-Kader, W., 2013, 'Transportation in reverse logistics enterprise: A comprehensive performance measurement methodology', Production Planning \& Control 24(6), 495-510. https://doi.org/10.1080/09537287.2011.634180

Steuer, R.E., 1986, Multiple criteria optimization: Theory, computation, and applications, Wiley, New York.

Subramoniam, R., Huisingh, D. \& Chinnam, R.B., 2010, 'Aftermarket remanufacturing strategic planning decision-making framework: Theory \& practice', Journal of Cleaner Production 18(16), 1575-1586. https://doi.org/10.1016/j.jclepro.2010. 07.022

Tari, I. \& Alumur, S.A., 2014, 'Collection center location with equity considerations in reverse logistics networks', INFOR: Information Systems and Operational Research 52(4), 157-173. https://doi.org/10.3138/infor.52.4.157

Temur, G.T., Kaya, T. \& Kahraman, C., 2014, 'Facility location selection in reverse logistics using a type-2 fuzzy decision aid method', in C. Kahraman \& B. Öztayş (eds.), Supply chain management under fuzziness, pp. 591-606, Springer, Berlin. https://doi.org/1-0.1007/978-3-642-53939-8_25

Tiwari, R.N., Dharmar, S. \& Rao, J.R., 1987, 'Fuzzy goal programming - An additive model', Fuzzy Sets and Systems 24(1), 27-34. https://doi.org/10.1016/0165 0114(87)90111-4

Wath, S.B., Dutt, P.S. \& Chakrabarti, T., 2011, 'E-waste scenario in India, its management and implications', Environmental Monitoring and Assessment 172(1-4), 249-262. https://doi.org/10.1007/s10661-010-1331-9

Xianfeng, L., Jianwei, Q. \& Meilian, L., 2010, 'Design and simulation WEEE reverse logistics network in Guangxi', in IEEE 2010 International Conference on Optoelectronics and Image Processing (ICOIP), Haiko, Hainan, China, November 11-12, 2010, vol. 1, pp. 403-408. https://doi.org/10.1-109/ICOIP.2010.253

Yang, C.L., Chuang, S.P., Huang, R.H. \& Tai, C.C., 2008, 'Location selection based on AHP/ANP approach', in IEEE International Conference on Industrial Engineering and Engineering Management, 2008. IEEM 2008, Singapore, December 08-10, and Engineering Management, 2008. IEEM 2008, Singapore, Decemb

Zavadskas, E.K., Kaklauskas, A., Turskis, Z. \& Tamošaitiene, J., 2008, 'Selection of the effective dwelling house walls by applying attributes values determined at intervals', Journal of Civil Engineering and Management 14(2), 85-93.

Zhang, D.Z., 2013, 'An integrated production and inventory model for a whole manufacturing supply chain involving reverse logistics with finite horizon period', Omega 41(3), 598-620. https://doi.org/10.1016/j.omega.2012.07.001

Zhang, S.Z. \& Lee, C.K.M., 2013, 'Optimization of facility location problem in reverse logistics network using Artificial Bee Colony algorithm', in 2013 IEEE International Conference on IEEE, Industrial Engineering and Engineering Management (IEEM) Bangkok, Thailand, December 10-13, 2013, pp. 1348-1352. https://doi.org/ 10.1109/IEEM.2013.6962630

Zhou, X. \& Zhou, Y., 2015, 'Designing a multi-echelon reverse logistics operation and network: A case study of office paper in Beijing', Resources, Conservation and Recycling 100, 58-69. https://doi.org/10.1016/j.resconrec.2015.04.009

Zimmermann, H.J., 1978, 'Fuzzy programming and linear programming with several objective functions', Fuzzy Sets and Systems 1(1), 45-55. https://doi.org/10.1016/0165-0114(78)90031-3 


\section{Appendix 1}

Consider the following multiple objective programming (MOP) problem (Steuer 1986:1):

$\operatorname{Max} F(x)=\left(f_{1}(x), f_{2}(x), \ldots . . f_{k}(x)\right)$

subject to $\mathrm{x} \in \mathrm{S}=\left\{g_{j}(x) \geq 0, j=1,2 \ldots, m\right\}$

Because of the incompatibility of the objectives, a unique feasible solution which optimises all the objectives of the above MOP problem simultaneously does not exist. Generally in real scenario, the DM compromises on choosing an efficient solution to the MOP problem, which is defined as follows:

Definition 1: $x^{*} \in S$ is said to be an efficient solution of MOP problem if there does not exist any $x \in S$ such that $f_{i}(x) \geq f_{i}\left(x^{*}\right) \forall \mathrm{i}=1,2, \ldots k$ and $f_{i}(x)>$ $f_{i}\left(x^{*}\right)$ for some $i \in\{1,2, \ldots k\}$

Definition 2: An efficient solution $x^{*} \in S$ is said to be a properly efficient solution of MOP problem if there exists a scalar $M>0$ such that, for each $i$ and $x \in S, f_{i}(x)-f_{i}\left(x^{*}\right) \leq M\left(f_{r}\left(x^{*}\right)-f_{r}(x)\right)$ for some $r$ with $f_{r}\left(x^{*}\right)>f_{r}(x)$ and $f_{i}(x)>f_{i}\left(x^{*}\right)$

The efficient solution represents a compromised solution; however, a properly efficient solution represents a better compromised solution, which is definitely preferred by DMs for solving the MOP problem.

Geoffrion (1967:2) proposed the following equivalent scalar problem (SP) for finding properly efficient solution of the MOP problem and proposed Lemma 1:

$$
\text { Maximise } \sum_{i}^{k} \lambda_{i} f_{i}(x)
$$

subject to $\mathrm{x} \in S, \lambda \in R^{k}, \sum_{i}^{k} \lambda_{i}=1, \lambda_{i} \geq 0 \forall i=1,2, \ldots k$

Lemma 1: An optimal solution $x^{*}$ of (SP) is a properly efficient solution of (MOP) problem. 